\title{
Research on Developing the Core Literacy System of Primary and Secondary School Students in Chinese Rural Areas
}

\author{
Huaruo Chen ${ }^{1}$, Ya Wen ${ }^{*}$ \\ ${ }^{1}$ School of Education Science, Nanjing Normal University, Nanjing, China \\ ${ }^{2}$ School of Teachers and Education, Nanjing Xiaozhuang University, Nanjing, China \\ Email: *ywen1133@126.com
}

How to cite this paper: Chen, H. R., \& Wen, Y. (2021). Research on Developing the Core Literacy System of Primary and Secondary School Students in Chinese Rural Areas. Open Journal of Philosophy, 11, 215-228.

https://doi.org/10.4236/ojpp.2021.112017

Received: March 22, 2021

Accepted: April 27, 2021

Published: April 30, 2021

Copyright $\odot 2021$ by author(s) and Scientific Research Publishing Inc. This work is licensed under the Creative Commons Attribution International License (CC BY 4.0).

http://creativecommons.org/licenses/by/4.0/

\begin{abstract}
The Ministry of Education of China put forward the concept of "core literacy system" for the first time in the "Opinions on Comprehensively Deepening Curriculum Reform and Implementing the Fundamental Tasks of Moral Education" issued in 2014. This is a new educational reform policy put forward by China based on fully combining China's national conditions and the new requirements for human development in the 21st century, which has important guiding significance for China's educational reform. After discussing the background, content, and meaning of core literacy, this study points out the current situation and development trend of core literacy in primary and secondary schools in China and then puts forward guiding opinions on the development of core literacy in rural primary and secondary schools. With the widening gap between urban and rural education, rural people are in urgent need of high-quality educational resources. To narrow the gap between urban and rural education and promote the democratization of education in China, we must unswervingly implement the education reform with the core element system as the key field and main link. This is also the significance of this study.
\end{abstract}

\section{Keywords}

Core Literacy System, Primary and Secondary School, Students, China, Rural Areas

\section{Introduction}

The term "core literacy" was not put forward by China for the first time. At the 
beginning of this century, OECD took the lead in putting forward the structural model of "core literacy", which pointed to achieving a successful life and developing a sound society (Qiu et al., 2019). All over the world, the core literacy put forward by various countries and regions has its unique connotations, although it is the acquaintance. The core literacy of China attaches importance to the education of students' attitudes and values, which is reflected from three dimensions: knowledge and skills, process and methods, and emotional attitudes and values (Hu, 2019). However, there are few studies on core literacy in rural China, which is the significance of this study.

\section{Core Literacy}

\subsection{Background}

Internationally, since the beginning of the 21st century, all countries and organizations have put forward the core literacy with their characteristics according to actual conditions and forecasts for the development of the 21st century. For example, the core literacy of the European Union emphasizes lifelong learning, while the core literacy framework of the United States is the "21st Century Learning Framework", which aims to enable students to have the vocational skills needed in the 21st century, achieve results and attach importance to financial and business literacy (Lee \& Hung, 2012). From the importance attached by various countries and organizations to core literacy, it can be seen that cultivating students' core literacy is the development direction of future education reform and the beginning of a new round of talent competition. In the understanding of core literacy, all countries and organizations generally believe that core literacy is the key to students' success and high-quality life in the 21st century.

It is pointed out that the core literacy with the core of "all-round development" is to push forward China's educational reform in-depth, which is of great significance to the implementation of the fundamental task of cultivating people by virtue. However, due to China's special national conditions, high-quality education has increasingly gathered in cities, which leads to the unbalanced development of education between rural areas and cities (Liu, 2004). The implementation of core literacy education will help improve the quality of rural primary and secondary education. Alleviate the contradiction between rural and urban areas due to the imbalance of educational resources. On the other hand, with the advent of the 21st century, the industrialized society is accelerating its transformation to an information-based and knowledge-based society (Becla, 2012). In the field of education, developing students' core literacy system is proposed to implement one of the fundamental tasks. Core literacy is an important means to comprehensively deepen curriculum reform, implement the concretization of moral education, enhance China's educational competitiveness, and implement our strategy of strengthening the country with talents and rejuvenating the country through science and education. 


\subsection{Basic Content}

China has realized that the changes of the times will put forward new requirements for education, and started to carry out curriculum reform. In this educational reform, emphasis is placed on developing quality education, training students to have the basic knowledge, basic skills, and methods of lifelong learning, and becoming new people with four talents. Major reforms have been made in curriculum objectives, curriculum structure, and curriculum standards. The Ministry of Education proposed a document that the core literacy system for students in each school section should be built, and clarify the necessary character and key ability that students should have to meet the needs of lifelong development and social development. In this document, it is emphasized to deepen the curriculum reform in an all-round way, and to carry out the more important task of building morality and educating people. It puts forward a new educational idea of putting moral education first, ability, and all-round development.

According to the reform opinions of the central government, a joint research group led by Beijing Normal University published its research results in 2016. According to the achievement of "Chinese Students' Development Core Literacy" published by them, it is pointed out that students' development core literacy refers to the necessary character and key ability that can meet the needs of lifelong development and social development ( $\mathrm{Hu}, 2019)$. In the document, it is considered that core literacy can be divided into three aspects, six major literacy, and 18 basic points. Three aspects refer to the cultural foundation, independent development, and social participation. Among them, the cultural foundation includes two major elements: humanistic background and scientific spirit. Humanistic connotation includes three basic points: humanistic accumulation, humanistic feelings, and aesthetic taste; scientific spirit includes three basic points: rational thinking, critical questioning, and courage to explore. Self-development includes learning to learn and living healthily. Among them, learning to learn includes three main points: being happy and good at learning, being diligent in reflection, and information awareness; Healthy living includes three basic points: cherish life, perfect personality, and self-management. Social participation includes responsibility and practice innovation. Among them, responsibility includes three basic points: social responsibility, national identity, and international exchange; practical innovation includes three basic points: labor consciousness, problem-solving, and technology application. The following figure fully shows the basic content of core literacy (Figure 1).

The above definition and division of core literacy mean that students can learn for life and become people who meet the needs of society. However, the definition of core literacy is also controversial in China. For example, some researchers think that the purpose of students' core literacy is to let students gradually form their personality characteristics and become complete individuals through learning, which can meet the development of individuals in the future life to a certain extent. While others believe that the essence of core literacy is to 


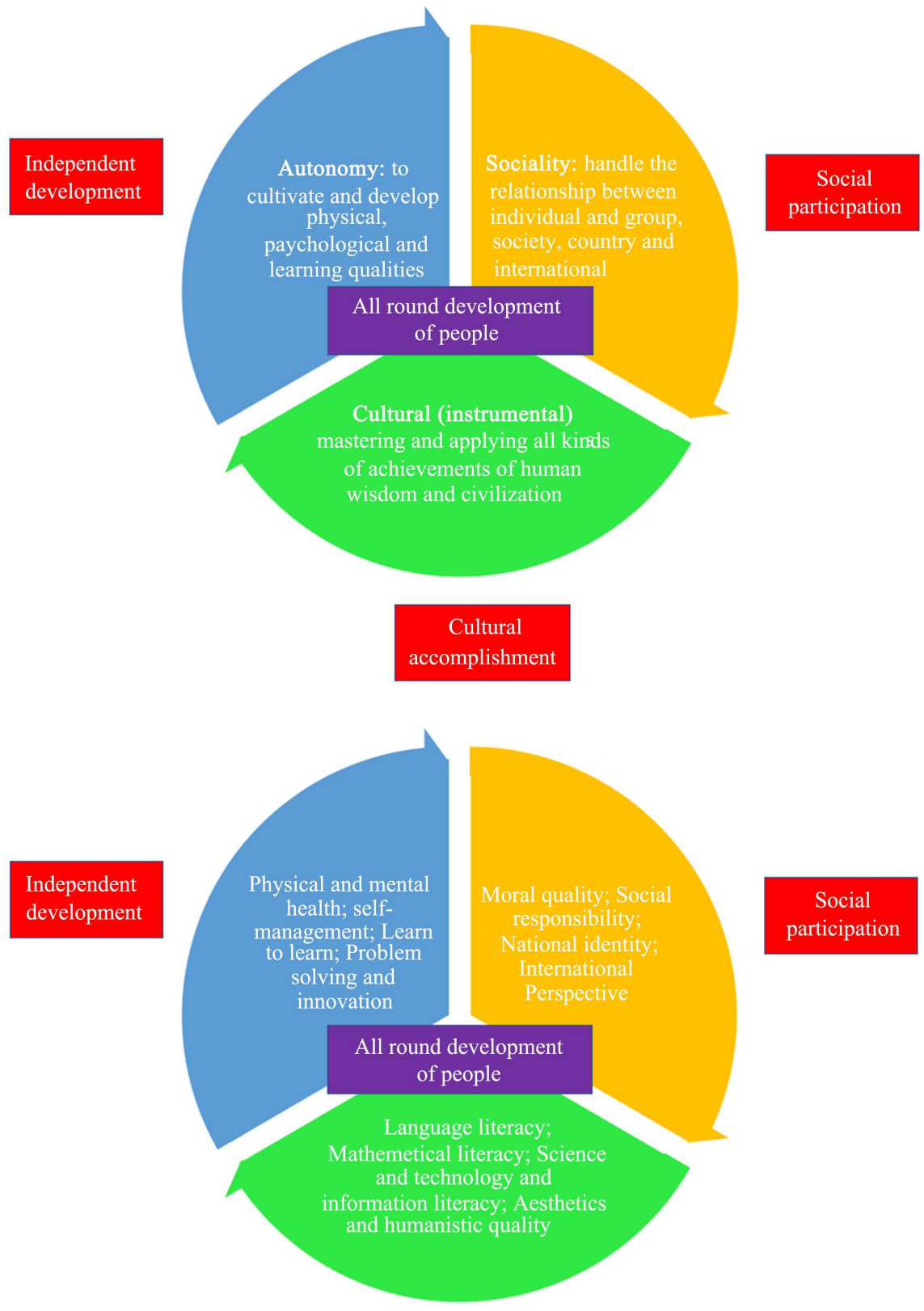

\section{Cultural}

accomplishment

Figure 1. The basic content of core literacy.

make students become cultured and intelligent people. At the same time, we can see that every core literacy definition refers to training students to be people with noble moral character, rational thinking, and successful life.

\subsection{Core Meaning}

China's core literacy is a concept with rich connotations, that is, it puts forward measures for the change of international education situation and fully combines China's national conditions. From an international point of view, China's core 
literacy is in line with the trend of international education reform, pointing to lifelong learning and lifelong education, and has strong international competitiveness. In the 21 st century, life-long learning is a quality that every individual must possess, and having the thought and ability of life-long learning cannot be eliminated by society (Wang \& $\mathrm{Hu}, 2012$ ). The lifelong education system is an important support for lifelong learning, and it should provide learning conditions for individuals in the best way when everyone needs to learn. Core literacy requires us to be prepared for lifelong education and lifelong learning. It also requires China to establish and improve the lifelong education system, and the society should strive to cultivate the cultural atmosphere of lifelong learning. On the other hand, with the continuous deepening of China's reform and opening-up, China's education is facing increasing pressure from international competition. How to maintain strong vitality and competitiveness in the fierce international education competition is a severe test for our education. Core literacy is the core of China's education reform, and its purpose is to enhance the quality of China's education so that China's education will go to the world and the future.

\section{The Current Situation of Rural Primary and Secondary Education in China}

Since the reform and opening up for decades, China's education has made brilliant achievements in both rural and urban areas, which has greatly improved China's education level (Sun, 2014). China's education system has trained countless outstanding talents for China's socialist modernization. Especially, the popularization of nine-year compulsory education has greatly promoted the development of rural education in China, and the number of students enrolled and graduates have been greatly improved. Moreover, China has eliminated "illiteracy" and raised the cultural level of the rural population.

\subsection{China's Primary and Secondary Education Achievements since the Reform and Opening-Up}

Judging from the popularization of compulsory education in China, from 1980 to 2000, China achieved the grand goal of basically popularizing compulsory education. In 2008, the enrollment rate of school-age children in China reached $99.5 \%$. By the end of 2008, the population coverage rate of universal compulsory education in China reached $99.7 \%$, and the number of counties that achieved the "Nine-Year Plan" accounted for $99.1 \%$ of the total number of counties in China. The net enrollment rate of primary-school-age children reached $99.54 \%$, and the consolidation rate of primary school in five years reached $99.5 \%$. The gross enrollment rate in junior middle school reached $98.5 \%$, and the consolidation rate in three years in junior middle school reached $93.7 \%$.

Judging from the changes in the number of teachers and teachers' educational background in China, the total number of full-time teachers in primary schools in 1996 was 5.736 million, of which $90.9 \%$ graduated from secondary schools or 
high schools. By 2002, 98\% had graduated from secondary school or high school. By 2008, the number of full-time teachers in primary schools had reached $5,621,900$, and the qualification rate of education had reached $99.27 \%$. In 1996, there were 2.932 million full-time teachers in junior middle schools, an increase of 29 percentage points over 1990. From the above data, we can see that although the number of full-time teachers in primary schools has decreased, this is due to the decline in the number of primary school students in China. On the other hand, although the number of teachers has decreased, the quality of teachers has been improved.

From the perspective of China's investment in education, China's education expenditure in 1995 was 187.795 billion yuan, of which 102.839 billion yuan was allocated in the national budget, accounting for $16.22 \%$ of the fiscal expenditure; Compared with 43.39 billion yuan in 1990, it increased by 3.3 times; In 1995, the proportion of public education funds to GNP was $2.46 \%$. In order to speed up the process of popularizing compulsory education in poverty-stricken areas, the central government increased the transfer of funds by 3.9 billion from 1995 to the end of the 20th century. In 2007, China's education expenditure reached 828.021 billion yuan, accounting for $16.63 \%$ of China's fiscal expenditure. From the above data, we can see that China's investment in education is increasing, and the proportion of growth in fiscal expenditure is also increasing.

Education determines the future of a country and a nation and is the most fundamental cause of a nation. However, the Chinese government always insists on placing education in an important position in China's modernization construction, and "escort" the development of education in China. From the above statistics, we can see that China's investment in education is ensuring sustained and steady growth, which reflects the level of China's economic development. The times are changing and developing, and our education industry should continue to deepen its reform along with the trend of the times. This is not only the mission given to us by the times but also the requirement of our "one-hundred-year plan". After decades of development, China's education has provided a solid material foundation for curriculum reform with the core of developing students' core literacy system. However, how to promote the development of education in the new round of education reform, especially how to fill the gap between rural and urban primary and secondary education development and cultivate the core literacy of rural primary and secondary school students, is worthy of our in-depth study.

\subsection{The Gap between Rural and Urban Primary and Secondary Education}

There is a huge gap between rural and urban education in China, which has a long history (Liu et al., 2014). On the one hand, it is due to the special national conditions of China, and on the other hand, it is caused by the unbalanced economic development in China, which makes a huge gap between rural and urban primary and secondary education in China, and now this gap is still showing a 
trend of continuous expansion. The gap between rural and urban primary and secondary education can be said to be reflected in all aspects of the whole primary and secondary education. This gap can be divided into two aspects, one is the external environment gap, but the internal environment gap.

First of all, the difference of external environment mainly refers to the difference of students' living environment, which includes both social environment and family environment. In terms of the social environment, children in rural areas live in a closed and backward environment, with inconvenient transportation and few places and facilities available for study. The living environment of children in urban areas is more open, and the transportation is faster and more convenient (Han et al., 2016). An open environment is conducive to children's contact with higher vision and more open and creative thinking. One of the benefits brought by convenient transportation is the expansion of children's range of activities, which is conducive to his access to a wider space. Children in cities also have many places and facilities for study, such as libraries, museums, science and technology museums, children's palaces, and so on. The family environment is mainly influenced by parents. On the one hand, the basic situation of parents will affect children's education. The basic situation of parents includes their knowledge level, education methods, and so on. As far as rural and urban areas are concerned, the educational level of parents in urban areas is generally higher than that in rural areas, which also leads to different educational methods adopted by each other. Perhaps parents in rural areas may adopt more authoritative management, while parents in urban areas may adopt more democratic education methods. On the other hand, parents' investment in children's education will also have an important impact on students' education (George \& Mensah, 2010). According to the statistics of the China Bureau of Statistics, in 2016, the per capita disposable income of urban residents was 33,616 yuan, while that of rural residents was 12,363 yuan. The huge income gap will inevitably lead to a huge gap in parents' investment in children's education, so the educational services that children enjoy will be very different.

Secondly, the internal environment gap between rural and urban primary and secondary education mainly refers to the gap between schools themselves. The facilities of primary and secondary schools in rural areas are relatively backward and the teachers are weak; On the contrary, primary and secondary schools in urban areas have complete and advanced school facilities and strong teachers. Especially in terms of teachers, the gap between rural and urban primary and secondary schools is particularly obvious and difficult to make up. The gap of teachers' strength is firstly reflected in the scale of teachers, which is mainly reflected in the overall number of teachers in schools, and secondly in the allocation of teachers. The allocation of teachers mainly refers to the number of teachers allocated to each class and each subject. In schools in rural areas, many teachers have to teach many classes, and even some teachers have to teach many different subjects, which will seriously affect the quality of teaching (Karanezi, 2014). The gap of teachers' strength is also reflected in the quality of teachers, 
including their educational background and professional titles.

\subsection{The Need to Develop the Core Literacy System of Rural Primary and Secondary School Students}

At the 18th CPC National Congress, it was mentioned that a well-off society should be built in an all-round way by 2020 . The key to building a well-off society in China depends on the countryside, while the building of a well-off society in China side depends on our rural education. "Education is the first priority". Only by doing a good job in education in rural areas of China can China build a well-off society in an all-round way faster and better.

First of all, developing the core literacy system of rural primary and secondary school students will help narrow the gap between urban and rural education and promote the democratization of education. One of the central contents of educational democracy is the equality of education. The equality of educational opportunities is the foundation of educational equality. With the development of the times, the equality of educational opportunities initially emphasizes the equality of entrance opportunities, then emphasizes the equality of educational years, schools and courses, and now emphasizes the equality of educational process and educational results. The core literacy system clearly requires students to have the necessary character and key ability to meet the needs of lifelong development and social development, emphasizing personal cultivation, social care, feelings of home and country, and paying attention to independent development, cooperative participation, and innovative practice. This ensures the equality of educational results in China. Secondly, according to the core literacy system of students' development, the specific educational objectives and tasks of each school section and discipline are further clarified, and the relevant standards of curriculum teaching in universities and primary and secondary schools are improved. This ensures the equality of the curriculum nature of education in China. Educational democratization is one of the goals pursued by all educational reforms in the world today and has become the main educational policy in many countries. Pursuing the democratization of education is not only determined by the nature of our party and country but also the most urgent need of our broad masses of people, especially those in rural areas.

Secondly, developing the core literacy of rural primary and secondary school students is conducive to improving the competitiveness of rural primary and secondary school students. According to relevant statistics, among the top universities in China, Tsinghua University and Peking University, the proportion of rural students is getting lower and lower, and it will only account for about $10 \%$ by 2016. According to relevant research, rural children have become increasingly remote from the beginning of school, and the Matthew effect of Chinese education has become increasingly fierce. The core literacy system mainly changes this phenomenon of "the stronger the strong, the weaker the retarded" from two aspects. Before that, we simply divided the education that people received in their whole life into two aspects, one is the school education that people received, and 
the other is the non-school education that people received. First, the core literacy system changes this situation in school education. According to the Opinions of the Ministry of Education on Comprehensively Deepening the Curriculum Reform and Implementing the Fundamental Tasks of Moral Education, it is necessary to clarify the degree requirements that students should meet after completing the learning contents of different classes, grades, and disciplines, and guide teachers to accurately grasp the depth and breadth of teaching so that the examination evaluation can more accurately reflect the requirements of personnel training. To enhance the suitability of disciplines, the learning contents of each discipline should conform to the age characteristics of students at different stages of development, and be closely related to their life experiences. Secondly, the core literacy system changes this situation in non-school education. The Ministry of Education will organize research and put forward the core literacy system of students' development in each school section, clarify the essential character and key ability that students should have to adapt to the needs of lifelong development and social development, and further refine and select the essential and basic knowledge content of students' all-round development and lifelong development in the subject textbooks.

Finally, developing the core literacy of rural primary and secondary school students is conducive to promoting the construction of new socialist countryside in China. The function of core literacy is to promote the civilization of rural customs, improve the quality of the rural population and promote the management of democracy in rural areas. To build a new socialist countryside, it is necessary to have "a new countryside of things" and "a new countryside of people". Improving the population quality in our rural areas is an important task in our new rural construction. In the "people's new rural construction", the core literacy system plays a connecting role. Inheriting the core literacy system can improve people's quality and promote rural civilization. It can cultivate a new generation of high-quality farmers.

\section{The Measures to Develop the Core Literacy System for Primary and Secondary School Students in Rural Areas}

Developing the core literacy system of primary and secondary school students in rural areas has become an important means to narrow the gap between urban and rural education and promote educational equity in China. To develop the core literacy system of primary and secondary school students, we need an excellent team of teachers, scientific and reasonable infrastructure, and a perfect curriculum system. Therefore, this study puts forward the suggestions of cultivating rural core literacy from three aspects: curriculum construction, teachers' construction and supporting facilities construction.

\subsection{The Curriculum Construction of the Core Literacy System}

To cultivate students' core literacy system, the curriculum should be constructed and implemented first. Strengthening the curriculum construction of the core 
literacy system mainly includes updating curriculum objectives, adjusting curriculum content structure, innovating the curriculum implementation process, and reforming curriculum evaluation.

First of all, the goal of updating the curriculum is to return to the question of "who to train". At present, there are two main ways to bring core literacy research results into curriculum reform: direct guidance and complimentary accommodation. However, China mainly adopts a complementary accommodation type, which defines the degree requirements that students should meet after completing the learning contents of different classes, grades, and disciplines. This division of teaching objectives between school sections and grades is conducive to the convergence of teaching objectives between different classes. Because the teaching goal of the lower grade is the foundation of the teaching goal of the upper grade, and it is the development and deepening of the teaching goal of the lower grade. However, the teaching objectives of different disciplines are complementary and accommodating. They are the refinement of the core literacy system, but the emphasis is different.

The adjustment of curriculum content is how to embody and implement in various disciplines according to the requirements of cultivating students' core literacy. Different disciplines set different training objectives, but the training objectives of different classes are different in degree. For example, in order to cultivate Chinese students' information literacy, we use information technology courses as a platform in primary schools to let students know about computers, their composition, and other knowledge.

The innovation of curriculum implementation requires our teachers to innovate in teaching practice and accurately grasp the depth and breadth of teaching. In Japan, they have established a curriculum implementation mode that aims at learning content, uses methods and means, and cultivates quality and ability through learning activities. However, due to the particularity of educational activities, the ultimate goal lies in the actual work of teachers. This requires us to further train teachers, and put relevant teaching concepts and theories into practice for teachers in the front line of teaching work. Let teachers always carry out teaching work around the core literacy system.

In China, curriculum evaluation is mainly based on students' test scores. A high score means that the teaching effect of this course is good, and a low score means that the implementation of this course is poor. This score-centered curriculum evaluation is very narrow, which limits teachers' creativity in teaching and the improvement of students' quality. China's curriculum evaluation reform can learn from foreign research results, such as a series of evaluation systems developed by the PISA project. For example, they define reading literacy as the ability to understand, use and reflect on texts in order to achieve personal goals, develop personal knowledge and potential, and strengthen social participation. When drawing lessons from other people's research results, we should combine with China's core literacy system and not copy it. 


\subsection{The Teachers' Construction of Rural Primary and Secondary Schools in China}

According to the suggestions of curriculum construction, it is necessary to establish teachers to ensure the effective development of the curriculum. In the establishment of the core literacy training system for rural primary and secondary school students, the overall quality of teachers plays a key role in education reform and development. However, due to the low level of rural economic development, backward infrastructure and difficult conditions, many young teachers and excellent teachers are unwilling to teach in rural primary and secondary schools, resulting in the aging of rural teachers and backward educational concepts. Many young teachers and excellent teachers are unwilling to teach in rural primary and secondary schools, which leads to the aging of rural teachers and the backwardness of educational ideas and concepts. Therefore, this study puts forward the following suggestions on the part of teacher construction.

First of all, we should strengthen the introduction of new teachers. A great team of teachers should be reasonably matched by the old, middle-aged, and young. If the proportion of young teachers is too small, there will be no successors. Besides, it is difficult to popularize and apply new educational concepts in the front line of education. Therefore, rural primary and secondary schools can establish cooperative relations with universities, so that universities can train teachers for rural primary and secondary schools. Governments at all levels should increase investment to improve and guarantee the wages of rural teachers. Governments at all levels and education departments should strengthen publicity to attract outstanding members of the public to join education.

Secondly, it should strengthen the training of in-service teachers. On the one hand, teachers' profession needs continuous learning in order to master new knowledge and new teaching ideas. On the other hand, it helps teachers improve their quality and promote their career development. The training of new teachers should focus on strengthening their professional identity and teaching skills. For old teachers, it is necessary to strengthen the cultivation of their professional ability, mainly by teaching them some new educational concepts, teaching concepts, and related policies and regulations. At the same time, we should pay attention to strengthening teachers' moral education and cultivating teachers with noble moral character.

Finally, the government and schools should work together to create a social atmosphere that respects teachers. First of all, it can enhance teachers' professional identity and meet teachers' demand for respect. Everyone wants to have a certain social status and be recognized by others and society, especially teachers. Secondly, it can enhance teachers' sense of professional belonging and make teachers more willing to devote themselves to our education. Third, we can attract more talented people to join our education. Fourth, it can better stimulate our teachers' initiative and creativity. 


\subsection{Scientific and Reasonable to Strengthen and Improve the Facilities of Primary and Secondary Schools in Rural Areas}

There are some problems in rural primary and secondary schools in China, such as poor teaching equipment, imperfect infrastructure, and unreasonable allocation of teaching equipment. However, building scientific, reasonable, and perfect rural primary and secondary school facilities is the material basis for developing students' core literacy system. Therefore, only on a complete material basis can our teachers teach better and students learn better.

First of all, for rural primary and secondary schools with poor teaching equipment and imperfect infrastructure, relevant departments should increase investment and improve infrastructure and equipment. At the same time of increasing investment, relevant departments should make scientific and reasonable plans, and make different transformation plans according to the specific conditions of each school. For example, if some schools need new teaching buildings and dormitories, new teaching buildings and dormitories should be built for them. However, some schools do not need to build new teaching buildings but need to replace equipment, such as the multimedia renovation of classrooms.

Secondly, there is a lack of scientific allocation of relevant teaching facilities and equipment, which needs to be optimized reasonably. Especially in some areas with good economic development in China, there are mainly the following performances: first, repeatedly configure related equipment; the second is to configure irrelevant equipment. For example, every primary and secondary school is equipped with a large number of musical instruments, but the whole school has no relevant professional teachers, resulting in a waste of equipment. Finally, the configured device is not used correctly. Therefore, for schools with the unreasonable allocation of teaching equipment, a scientific allocation scheme should be made to give full play to the effectiveness of relevant teaching equipment. At the same time, when configuring related equipment, on the one hand, it is necessary to train teachers on related usage methods, so that they can use the equipment correctly and fully. On the other hand, establishing an efficient and perfect follow-up service and maintenance system should not give people an attitude of doing things well.

\section{Conclusion}

Developing students' core literacy system is of great significance for deepening the curriculum reform in China and implementing the fundamental task of cultivating people by virtue, and it is the key field and main link of China's education reform. Since the reform and opening up, for the overall goal of China, China has been sacrificing the interests of rural areas to "nurture" the development of urban areas. Nowadays, when we have made great achievements in reform and opening up, we think the first thing we should do is to promote the development of education in rural areas. On the other hand, the development of rural education is directly related to building a well-off society in an all-round 
way and realizing socialist modernization. Relying on the core literacy system, reforming rural education in China will improve the fairness of education in China, promote the democratization of education in China, enhance people's sense of acquisition and happiness in rural areas, and alleviate the contradiction between urban and rural areas on education.

\section{Acknowledgements}

The authors would like to thank the reviewers for their valuable comments on the manuscript.

\section{Funding}

This research was funded by a Jiangsu Graduate Innovation Project, grant number "KYCX20_1145" and Jiangsu Province University's Advantageous Discipline Construction Project, grant number "PAPD".

\section{Conflicts of Interest}

The authors declare no conflicts of interest regarding the publication of this paper.

\section{References}

Becla, A. (2012). Information Society and Knowledge-Based Economy-Development Level and the Main Barriers-Some Remarks. Economics \& Sociology, 5, 125-132. https://doi.org/10.14254/2071-789X.2012/5-1/8

George, D. D., \& Mensah, D. K. D. (2010). Parental Involvement in Home Work for Children's Academic Success. A Study in the Cape Coast Municipality. Academic Leadership Journal, 8, 110-115.

Han, Y., Zhang, Y., \& Yang, X. (2016). Analysis on the Differences of Pre-School Education Development in Western China from the Perspective of Balanced Urban and Rural Areas Development-Taking Chongqing City as an Example. Open Journal of Social Sciences, 4, 115-121. https://doi.org/10.4236/jss.2016.42016

$\mathrm{Hu}$, Z. (2019). Chinese Mathematics Teaching Reform Based on the Guidance of Core Literacy. Creative Education, 10, 3410-3419. https://doi.org/10.4236/ce.2019.1013263

Karanezi, X. (2014). Primary and Lower Secondary School Teachers: Teachers' Attitudes and Perceptions about Traditional Teaching Methodologies and Modern Teaching Methodologies according to RWCT. Creative Education, 5, 1567-1575.

https://doi.org/10.4236/ce.2014.516173

Lee, S.-S., \& Hung, D. (2012). Is There an Instructional Framework for 21st Century Learning? Creative Education, 3, 461-470. https://doi.org/10.4236/ce.2012.34071

Liu, F. (2004). Basic Education in China's Rural Areas: A Legal Obligation or an Individual Choice? International Journal of Educational Development, 24, 5-21. https://doi.org/10.1016/j.ijedudev.2003.09.001

Liu, X. Z., Li, L., \& Du, C. Y. (2014). Evaluation on the Efficiency of Policy Implementation for Teacher Mobility of Compulsory Education between Rural and Urban Areas in China. Chinese Studies, 3, 74-81. https://doi.org/10.4236/chnstd.2014.32011

Qiu, Y., Lu, X., Fu, T., \& Du, D. (2019). Analysis of China’s Core Literacy Research Based 
on Keyword Clustering. Creative Education, 10, 1002-1022.

https://doi.org/10.4236/ce.2019.105076

Sun, M. (2014). 30 Years of Chinese Educational Management: Achievements, Characteristics and Problems. International Journal of Educational Management, 28, 340-348. https://doi.org/10.1108/IJEM-04-2013-0058

Wang, X., \& Hu, Q. (2012). Research into the Improvement of College Students' Life-Long Learning Ability. Creative Education, 7, 69-72.

https://doi.org/10.4236/ce.2012.37B017 